Diabetic retinopathy also develops less often in diabetic

Journal of Ophthalmology Cases \& Hypotheses

\section{ON THE PATHOGENESIS OF DIABETIC RETINOPATHY, DAMAGE TO MULLER CELLS, DISEASES OF OPPONENTS, AND INFLAMMATION: A REVIEW}

\author{
Hajiyev R.V. MD, PhD.
}

Department of Ophthalmology, Azerbaijan State Advanced Training Institute for Doctors named after A.Aliyev (ASATID), Baku, Azerbaijan

\begin{abstract}
Purpose: The purpose of this article is to summarize the literature data of our thirty years research on the pathogenesis of diabetic retinopathy.

Methods: literature data of our and foreign studies.

Results and Conclusion:

Diabetic retinopathy is a chronic inflammatory process in the retina. It is known that all inflammatory processes occur in the glia. In the retina, one types of the glial cell are Müller cells. There are located between neurons and capillaries. It is their destruction that leads to increased vascular permeability and loss of pericytes.

Lipid peroxidation can damage Müller cells.

There is high activity of glutathione peroxidase in the vitreous body, which neutralize lipid peroxidation. Therefore, these enzymes help the retina neutralize toxic products. An absence of direct contact between the vitreous and the retina's antioxidant system will severely impair the protection of that part of retina against the harmful effects of lipid peroxidation lipoxidation, which in turn, will accelerate the disruption of cell membranes in retinal neuronal and glial elements, the loss of pericytes, and endothelial damage. Connective tissue can develop at the site of local vitreous detachment. Thus, in diabetic retinopathy, glial cells of the retina are primarily affected.

In diabetes, only the inner part of the retina is damaged, and photoreceptors remain intact. Thus, the inner and outer parts of the retina are opponents. We believe that the positive effect of panretinal laser photocoagulation on diabetic retinopathy is associated with the destruction of the photoreceptor (outer) layer of the retina. That is, artificial retinal dystrophy is induced. In addition, the centre of the retina and its periphery also have an opposing relationship.
\end{abstract}

encephalopathy, dementia. A "parquet type" fundus indicates a lack of blood supply to the vessels of the brain and a risk of ischaemic stroke.

The question is which microbiota is responsible for diabetic retinopathy and other acquired retinal diseases. This is an interesting question that we will answer.

Keywords: Diabetic retinopathy, Laser photocoagulation, inflammation, microbiota, glial cells.

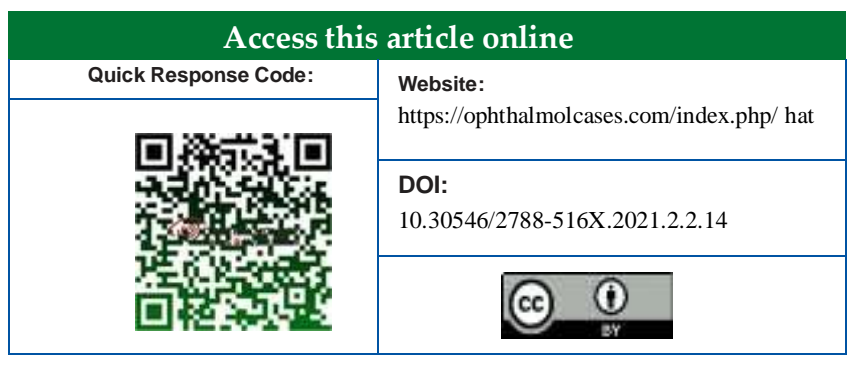

\section{Introduction}

Diabetic retinopathy (DR) is one of the largest causes of vision loss worldwide and is the principal cause of impaired vision in patients between 25 and 74 years of age $e^{1,2,3}$.

Clinically, diabetic retinopathy (DR) is divided into two stages: non-proliferative diabetic retinopathy (NPDR) and proliferative diabetic retinopathy (PDR).

NPDR represents the early stage of DR, in which increased vascular permeability and capillary occlusion are two main symptoms in the retinal vasculature. In this stage, retinal pathologies, including microaneurysms, haemorrhages and hard exudates, can be detected by fundus photography, although patients may be asymptomatic. PDR, a more advanced stage of DR, is characterized by neovascularization.

During this stage, patients may experience severe vision impairment when new abnormal vessels bleed into the vitreous (vitreous haemorrhage) or when tractional retinal detachment is present.

Journal of Ophthalmology Cases \& Hypotheses Volume 2, Number 2, 2021. 14-19= 
The most common cause of vision loss in patients with DR is diabetic macular edema (DME). DME is characterized by swelling or thickening of the macula due to sub- and intraretinal accumulation of fluid in the macula triggered by the breakdown of the blood-retinal barrier (BRB) ${ }^{4}$.

Many authors believe that leukostasis (leucocytes attached to the endothelial wall) and loss of pericytes are involved in the pathogenesis of diabetic retinopathy ${ }^{5,6}$.

Hyperglycaemia is considered to play an important role in the pathogenesis of retinal microvascular damage.

The earliest responses of the retinal blood vessels to hyperglycemia are dilatation of blood vessels and blood flow changes. These changes are considered to be a metabolic autoregulation to increase retinal metabolism in diabetic subjects ${ }^{7}$.

Pericyte loss is another hallmark of the early events of DR. Evidence of apoptosis of pericytes triggered by high glucose has been shown in both in vitro and in vivo studies ${ }^{8,9}$.

Since pericytes are responsible for providing structural support for capillaries, loss of them leads to localized outpouching of capillary walls. This process is associated with microaneurysm formation, which is the earliest clinical sign of DR ${ }^{10}$.

In addition to pericyte loss, apoptosis of endothelial cells and thickening of the basement membrane are also detected during the pathogenesis of DR, which collectively contribute to the impairment of the $\mathrm{BRB}^{11}$.

Furthermore, pronounced loss of pericytes and endothelial cells results in capillary occlusion and ischemia. Retinal ischemia/hypoxia leads to upregulation of VEGF through activation of hypoxia-inducible factor 1 (HIF-1) ${ }^{12}$.

Moreover, as an angiogenic factor, VEGF promotes proliferation of endothelial cells through activation of mitogen-activated protein (MAP) ${ }^{13}$.

DR has long been recognized as a microvascular disease.
I hypothesised that the vitreous fibrils are of intracellular origin ${ }^{16,17,18}$, which has been confirmed by immunocytochemical studies ${ }^{19}$.

Muller cells also form endfeet on the large retinal blood vessels at the inner surface of the retina. The surface of the Muller cell membrane facing the vitreous is covered with a mucopolysaccharide material and thus its processes are associated with the formation of the true basement membrane $^{20}$.

At the same time, some authors have reported that vitreous fibrils are linked directly with the basement membrane of retinal Müller cells ${ }^{21}$. They estimate the vitreoretinal interface to account for $95 \%$ of these cells membrane conductivity as regards potassium ions. That proves the region in question to be highly labile ${ }^{22}$. This process can apparently progress to the complete destruction of the vitreoretinal interface and the appearance of local vitreous detachment.

In 1985, I defended my dissertation entitled "The Effect of Lipid Peroxidation on the Course of Diabetic Retinopathy" at the Moscow Institute of Eye Diseases ${ }^{23}$. This thesis states that lipid peroxidation can damage Müller cells. Later, a paper on this topic was published in the journal "Ophthalmosurgery"24.

In my earlier studies, it was shown that there was high activity of glutathione peroxidase in the vitreous body ${ }^{25,26}$.

These enzymes neutralize lipid peroxidation, which forms as a result of the breakdown of rhodopsin. Therefore, these enzymes help the retina neutralize toxic products formed during the breakdown of rhodopsin.

An absence of direct contact between the vitreous and the retina's antioxidant system will severely impair the protection of that part of retina against the harmful effects of lipid peroxidation lipoxidation (Figure 1), which in turn, will accelerate the disruption of cell membranes in retinal neuronal and glial elements, the loss of pericytes, and endothelial damage. Connective tissue can develop at the site of local vitreous detachment ${ }^{24}$. Thus, in diabetic retinopathy, glial cells of the retina are primarily affected.

\section{The role of Muller cell damage}

In the studies I conducted from 1982 to 2004, it was shown that microvascular changes in the retina are secondary and that Müller's cells are primarily affected ${ }^{14}$. Müller's cells are glial cells that are located between neurons and capillaries, and their destruction leads to increased vascular permeability and the loss of pericytes. These effects, in turn, lead to extensive ischemic areas and the production of VEGF factors, which triggers the formation of new vessels. Müller cells are known to contain a yellow pigment, lipofuscin. Hard exudates in the outer plexiform layer do not release lipids but cause Mueller cell degeneration ${ }^{15}$. 


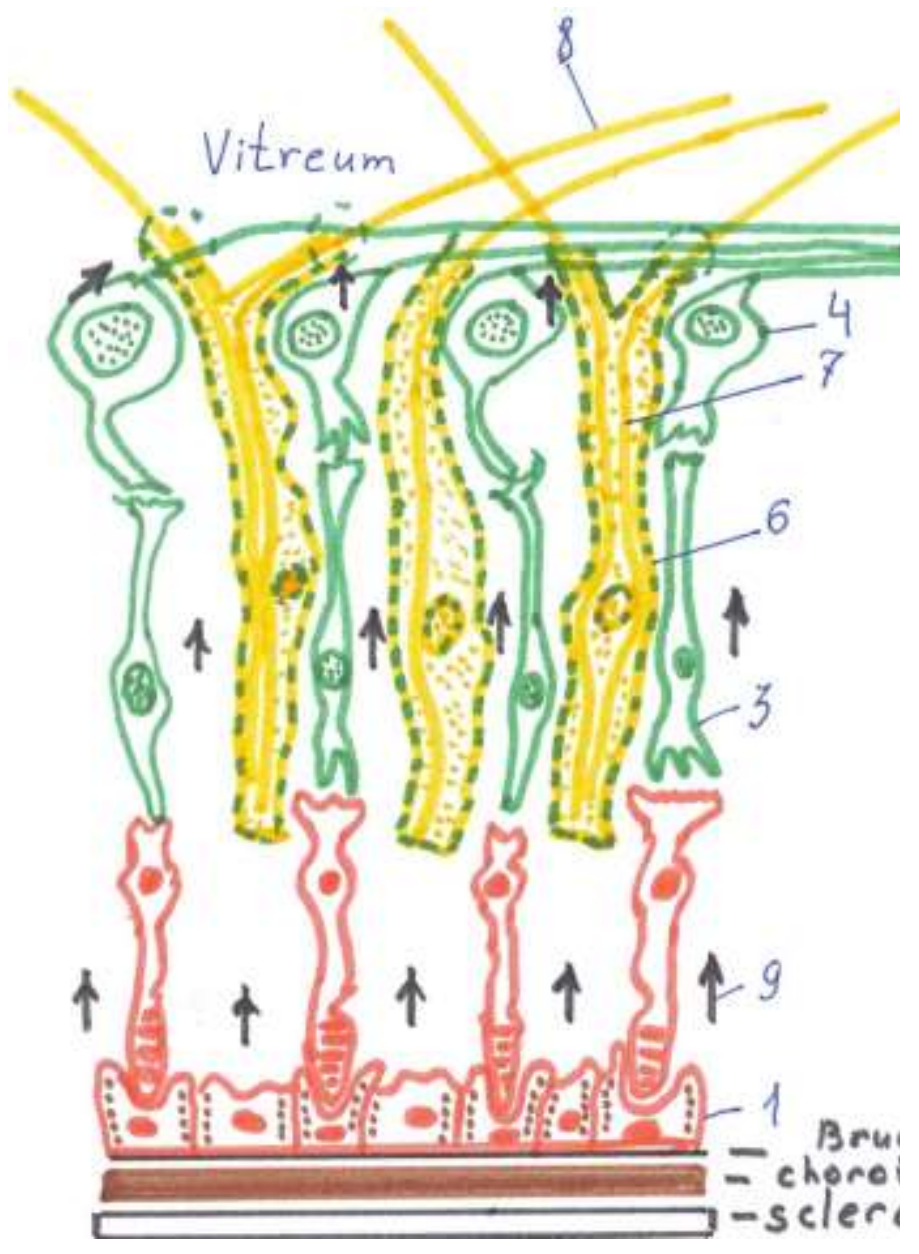

Figure 1. Schematic structure of the retina.

1 - pigment epithelium cells, 2 - axons of the ganglion cells, 3 bipolar cells, 4 - ganglion cells, 6 - Muller cells, 7 - intracellular fibrils, 8-vitreous fibrils, 9-toxic products formed during the breakdown of rhodopsin.

Our research results have begun to be confirmed by modern investigation ${ }^{26}$

Müller cells are the principal glial cells of the retina. Müller cells form architectural support structures that radially stretch across the thickness of the retina and are the limits of the retina at the outer and inner limiting membranes.

The figure 1 shows the retina in two colours. The green colour is the inner part of the retina, and the red colour indicates the outer part of the retina. I believe that the border between these parts is the outer boundary membrane.

\section{Theory about the diseases of opponents}

In diabetes, only the inner part of the retina is affected, and photoreceptors remain intact. However, some authors do not believe this is the case ${ }^{27}$.

Thus, the inner and outer parts of the retina are opponents. In some cases, diabetic retinopathy develops (changes in the inner part of the retina) without senile macular degeneration (changes in the pigment epithelium and photoreceptors).

In the presence of senile macular degeneration, diabetic retinopathy does not progress.
If, in diabetic retinopathy, the outer layers of the retina are involved in the process, then diabetic retinopathy does not progress, but senile macular degeneration begins. That is, diabetic retinopathy and senile macular degeneration are diseases that are induced in opposition to one another.

We believe that the positive effect of panretinal laser photocoagulation on diabetic retinopathy is associated with the destruction of the photoreceptor (outer) layer of the retina. That is, artificial retinal dystrophy is induced ${ }^{15,17}$. Various authors have observed that if atrophy of the optic nerve $^{28}$ or glaucoma occurs in the presence of diabetic retinopathy 29,30 , then retinopathy does not progress ${ }^{15}$.

In addition, the centre of the retina and its periphery also have an opposing relationship because they "contend" with one another, forming full-fledged vision. Azerbaijani physiologists have provided evidence of this relationship ${ }^{31,32}$.

Several channels carry visual information into the cortex: through the lateral geniculate body (corpus geniculatum laterale), through the upper tubercles (superior colliculi) of the quadruplet bodies (corpora quadrigemina) and through the more ancient path through the thalamus.

Information collected at the centre of the retina mainly passes through the lateral geniculate body and from the periphery of the retina through the upper tubercles of the quadruplet bodies.

These centres have an opposing relationship with each other. One centre slows the other. Study of oscillatory potentials has shown that when the upper tubercles of the quadruplet bodies are damaged, it is easier to carry information through the lateral geniculate body. These relationships are carried out both at the level of the subcortex and the cortex.

We observed a patient with retinitis pigmentosa who often said, "Today, I see better, but at the same time worse. A few days ago, I saw worse, but at the same time better". For a long time, I did not understand his words until I remembered the relationship between the centre and the periphery of the retina.

When his peripheral vision was improved (his field of vision was expanded), then, at that moment, he was better oriented, but his vision was worse (his central vision deteriorated). The next moment he saw better, but the deterioration of his peripheral vision led to a deterioration in his orientation in space. The same struggle takes place between the two eyes. Ophthalmologists often encounter patients in whom one eye sees worse than the other. Patients say that when they close the worse seeing eye, the vision of the other eye improves. This is because the inhibitory effect of the closed eye on the opposite eye is turned off.

Additionally, we observed for the first time that diabetic retinopathy develops less often with concomitant diabetic encephalopathy. At the same time, a "parquet type" (Figure 2) fundus is noted on the fundus, which indicates a lack of 
blood supply to the vessels of the brain and a risk of ischaemic stroke.

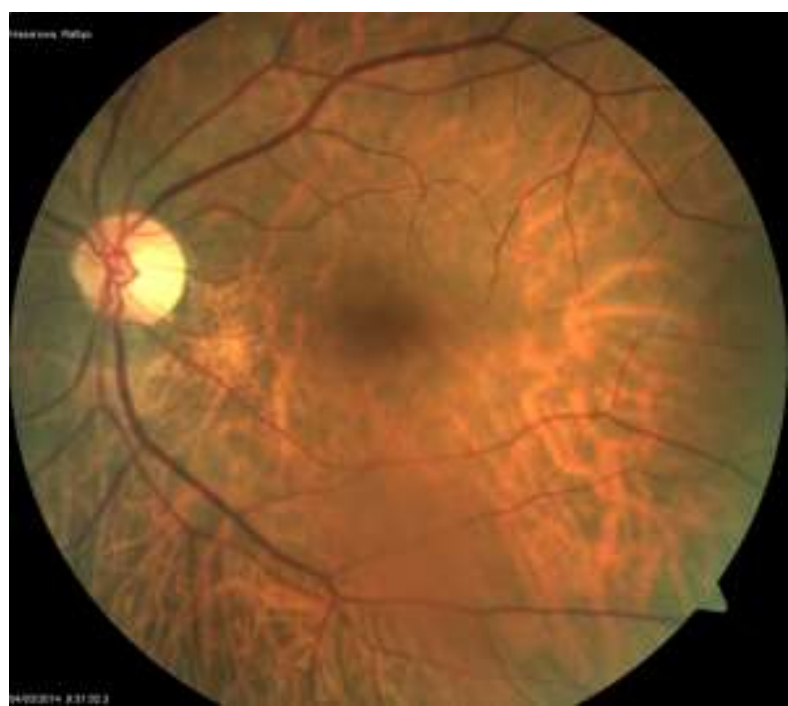

Figure 2. "Parquet type" of fundus.

Interestingly, even in the absence of diabetes, the presence of a "parquet" type fundus (in the absence of myopia) also indicates a risk of ischaemic stroke in elderly people. In 1997, I issued a methodological recommendation approved by the Ministry of the Republic of Azerbaijan for ophthalmologists and neuropathologists ${ }^{33}$.

Thus, the pathogenesis of diabetic retinopathy is based on damage to the glial cells of the retina. It is known that all inflammatory processes occur in glia.

\section{Composition of the commensal microbiota as a trigger of ocular diseases}

Connections between populations of microbiota and ocular disease are now being established. The roles of non-ocular microbiota in complex retinal diseases are being evaluated. For example, the gut microbiota has been implicated in the pathogenesis of uveitis. This short review summarizes the few studies linking the gut or oral microbiota to diabetic retinopathy (DR), glaucoma and age-related macular degeneration $(\mathrm{AMD})^{34}$.

\section{Conclusion}

The question is which microbiota is responsible for diabetic retinopathy and other acquired retinal diseases. This is an interesting question that we will answer.

\section{Conflict of interests}

The author declares that there is no conflict of interests.

\section{Data availability statement}

The data that support the findings of this study are available from the corresponding author upon reasonable request.

\section{Funding}

None.

\section{Study association}

This study is not associated with any thesis or dissertation work.

\section{References and notes:}

1. Willis JR, Doan QV, Gleeson M, et al. 2017 Vision-Related Functional Burden of Diabetic Retinopathy Across Severity Levels in the United States. JAMA Ophthalmol 2017; 135:926. doi: 10.1001/jamaophthalmol.2017.2553.

2. Mazhar K, Varma R, Choudhury F, et al. Severity of diabetic retinopathy and health-related quality of life: the Los Angeles Latino Eye Study. Ophthalmology 2011;118:649-655. doi: 10.1016/j.ophtha.2010.08.003.

3. Leasher JL, Bourne RR, Flaxman SR, et al. Global estimates on the number of people blind or visually impaired by diabetic retinopathy: A meta-analysis from 1990 to 2010. Diabetes Care 2016;39(9):1643-1649. doi.org/10.2337/dc15-2171

4. Romero-Aroca P., Baget-Bernaldiz M., Pareja-Rios A. et al. Diabetic macular edema pathophysiology: Vasogenic versus inflammatory. J. Diabetes Res 2016;2016:2156273. doi: $10.1155 / 2016 / 2156273$

5. Lutty GA, Cao J, McLeod DS. Relationship of polymorphonuclear leukocytes to capillary dropout in the human diabetic choroid. Am J Pathol 1997;151:707-14. PMID: 9284819

6. Barouch FC, Miyamoto K, Allport JR, et al. Integrinmediated neutrophil adhesion and retinal leukostasis in diabetes. Invest Ophthalmol Vis Sci 2000;41:1153-8. PMID: 10752954

7. Bek T. Diameter changes of retinal vessels in diabetic retinopathy. Curr. Diabetes Rep 2017;17(10):82. doi: 10.1007/s11892-017-0909-9

8. Naruse K., Nakamura J., Hamada Y., Nakayama M., Chaya S., Komori T., Kato K., Kasuya Y., Miwa K., Hotta N. Aldose reductase inhibition prevents glucose-induced apoptosis in cultured bovine retinal microvascular pericytes. Exp. Eye Res 2000;71:309-315. doi: 10.1006/exer.2000.0882

9. Romeo G., Liu W.H., Asnaghi V., Kern T.S., Lorenzi M. Activation of nuclear factor-kappaB induced by diabetes and high glucose regulates a proapoptotic program in retinal pericytes. Diabetes 2002;51:2241-2248. doi: 10.2337/diabetes.51.7.2241

10. Sohail Ejaz, Irina Chekarova, Ahmed Ejaz, Amara Sohail, Chae Woong Lim Importance of pericytes and mechanisms of pericyte loss during diabetes retinopathy. Diabetes Obes. Metab 2008;10:53-63. doi: 10.1111/j.1463-1326.2007.00795.x.

11. Beltramo E., Porta M. Pericyte loss in diabetic retinopathy: Mechanisms and consequences. Curr. Med. Chem 2013;20:3218-3225. doi: 10.2174/09298673113209990022

12. Huang H., He J., Johnson D., Wei Y., Liu Y., Wang S., Lutty G.A., Duh E.J., Semba R.D. Deletion of placental growth factor prevents diabetic retinopathy and is associated with Akt activation and HIF1alpha-VEGF pathway inhibition. Diabetes 2015;64:200-212. doi: 10.2337/db14-0016

13. Rousseau S., Houle F., Landry J., Huot J. p38 MAP kinase activation by vascular endothelial growth factor mediates actin reorganization and cell migration in human endothelial cells. Oncogene 1997;15:2169-2177. doi: 10.1038/sj.onc.1201380 
14. Hajiyev RV., Korkmazov BM., Qasanov IA. Changes in retinal glial cells in experimental diabetes mellitus (in Russian). In: Topical issues of theoretical and clinical morphology. Baku: Azerbaijan Medical University 1997:6,99103.

15. Hajiyev RV. Diabetic retinopathy (in Russian). Baku: Elm 1999:1-72.

16. Hajiyev RV. On the biomicroscopic structure of the vitreous body. Vestnik Oftalmologii 1992;5: Deposited at VINITI b/o 378 .

17. Hajiyev RV. Diabetic retinopathy and central retinal vein thrombosis (in Russian). Baku: Poligraphic production 2011:171.

18. Hajiyev RV. Biomicroscopic changes in the vitreous body depending on age, gerontological parallels (in Russian). In: Actual problems of ophthalmology. International conference abstracts. Baku, 2008:220-223.

19. Ponsioen TL, van Luyn MJA, van der Worp RJ,Pas $H H$, Hooymans JMM, Los LI. Human retinal Müller cells synthesize collagens of the vitreous and vitreoretinal interface in vitro. Mol Vis 2008;14:652-660. PMID: 18385800

20. Miller RF, Dowling JE. Intracellular responses of the Muller (glial) cells of the mudpuppy retina: their relation to bwave of the electroretinogram. J Neurophysiol 1970;33:323-341. DOI: 10.1152/jn.1970.33.3.323

21. de Juan EJ., Dickson J, Hatchell DL. Interaction of retinal glial cells with collagen matrices: Implications for pathogenesis of cell-mediated vitreous traction Graefe's Archive for Clinical and Experimental Ophthalmology 1989;227:494-498.

https://link.springer.com/article/10.1007/BF02172905

22. Newman EA. Membrane physiology of retinal glial (Muller) cells. NeuroSci 1985;5(8):2225-2239. DOI: 10.1523/JNEUROSCI.05-08-02225.1985

23. Hajiyev RV. Influence of some intraocular factors and lipoxidation on the course of diabetic retinopathy (in Russian), Abstract, Moscow: 1985:1-18.

24. Gajiyev RV. Posterior vitreous detachment in pathogenesis of diabetic retinopathy. Ophthalmosurgery (Russian) 1992;2:40-52.

25. Aliyeva ZA., Hajiyev RV., Kerimov BF. On the content of the components of the antioxidant system in the tissues of the eye. Azerbaijan Medical Journal 1983;3:62-64.

26. Aliyeva ZA, Sultanov MU, Hajiyev RV. Selenium content and activity of glutathione peroxidase enzymes in human eye tissues in diabetes. Vestnik Oftalmologii 1985;3:33-38.

27. Augustine J, Troendle EP, Barabas P, et al. The Role of Lipoxidation in the Pathogenesis of Diabetic Retinopathy Front Endocrinol (Lausanne). 2020; 11: 621938. Published online 2021 Feb 18. doi: 10.3389/fendo.2020.621938

28. Yanko L. Diabetic retinopathy in visual deprivation. A case report. Acta Ophthalmol (Copenh) 1980;58(2):283-287. doi: 10.1111/j.1755-3768.1980.tb05722.x

29. Becker B. Diabetes mellitus and primary open-angle glaucoma. XXYII Edward Jackson memorial lecture. AJO 1971;71(1):234-236. DOI: 10.1016/0002-9394(71)91088-9

30. Becker B, Bresnick G, Chevrette 1, et al. Intraocular pressure and its response to topical corticosteroids in diabetes. Arch Ophthalmol 1966;76(5):477-480. DOI: 10.1001/archopht.1966.03850010479003

31. Qasanov GG., Hajiyeva NA., Rzayeva NM. et al. Oscillatory evoked potentials in the visual system of a rabbit in experimental retinal pathology created by the administration of monoiodoacetic acid. Bulletin of Experimental Biology and Medicine 1985;9:289-292.

32. Hajiyeva NA Electrophysiological study of central regulation and heterosensory integration in the visual analyzer system (in Russian). Abstract of doctoral dissertation. Баку, 1969:1-79.

33. Hajiyev RV. Diagnostic technique for discirculatory and diabetic encephalopathy according to ophthalmoscopy data. Baku: Elm,1997:1-10.

34. Rowan S., Taylor A. The Role of Microbiota in Retinal Disease. In: Ash J., Anderson r., LaVail M., et al. (eds) Retinal Digenerative Deseases. Advances in Experimental Medicine and Biology 2018;1074:429-435. doi.org/10.1007/978-3-319-754024_53

How to cite this article: Hajiyev R.V. On the pathogenesis of diabetic retinopathy, damage to Mueller cells, diseases of opponents, and inflammation: a review. Ophthalmology Cases \& Hypotheses. 2021;02(02):14-18. 